\title{
ANALISIS KEBUTUHAN KAWASAN HUTAN KOTA BERDASARKAN EMISI KARBON DIOKSIDADI KOTA PIRU, SERAM BAGIAN BARAT
}

\section{ANALYSIS OF URBAN FOREST AREA NECESSARY BASED ON CARBON DIOXYDE EMISSION IN CITY OF PIRU, SERAM BAGIAN BARAT}

\author{
Sartje M. Untajana ${ }^{1)}$, Robert Oszaer ${ }^{2)}$, Yosevita. Th. Latupapua ${ }^{3)}$ \\ ${ }^{1)}$ Mahasiswa Pascasarjana, Program Study Manajemen Hutan Universitas Pattimura \\ ${ }^{2,3)}$ Dosen Pascasarjana Program Studi Manajemen Hutan Universitas Pattimura \\ E-mail : aceuntajana@gmail.com \\ \begin{tabular}{l|l} 
Diterima: 21 Juni 2019 & Disetujui: 5 Juli 2019
\end{tabular}
}

\begin{abstract}
Abstrak
Penelitian ini bertujuan untuk menentukan luas areal hutan kota berdasarkan estimasi emisi karbondioksida dari lalulintas kendaraan bermotor dan aktifitas pernapasan manusia di wilayah Piru dan sekitarnya. Hasil perhitungan terhadap emisi karbondiokasida akan dipakai sebagai dasar untuk menentukan proporsional luas hutan kota yang akan dibangun. Rencana luas hutan kota secara komprehensif mencakup jenis dan komposisi vegetasi didalamnya, dan diproyeksikan mampu menyerap emisi yang dihasilkan. Hasil analisis menunjukan jumlah emisi karbondioksida yang dihasilkan oleh lalulintas kendaraan di Kota Piru adalah sebesar 50.186,4 ton/tahun, sedangkan karbondioksida buangan yang dihasilkan oleh aktivitas pernapasan manusia adalah sebesar 9.499,47 ton/tahun. Luas lahan hutan kota yang diperlukan untuk menyerap emisi karbondioksida yang dihasilkan adalah sebesar 12,67 Ha. Perhitungan jarak tanam adalah 10 x 10 meter, dengan asumsi pemilihan tapak untuk penyerapan emisi karbondioksida terletak ditengah kota, sehingga tipe yang direkomendasikan adalah tipe rekreasi, yang secara komprehensif dapat menambah nilai estetika, serta menambah kenyamanan kota Piru kedepan. Jumlah spesies dalam hutan kota terdiri dari 21 jenis dimana $30 \%$ dari luas hutan kota diperuntukan sebagai ruang terbuka untuk interaksi masyakat di dalamnya, maka jumlah vegetasi pohon yang perlu ditanam adalah sebanyak 620,56 individu.
\end{abstract}

Kata kunci : hutan kota, emisi karbondioksida, kendaraan bermotor, vegetasi.

\begin{abstract}
The objective of the study is to determine urban forest area, based on carbon dioxyde emission estimation from vehicle traffic and human activities in the city and around. The result of carbon dioxyde emission calculation used as a basic to determine proportional forest area to established. The comprhensive plan of urban forest, covers species and vegetation type that projected to be able to abrsorb the emission. The analysis shows that amount of carbon dioxyde emission from vehicle traffic in the city was 50,186.4 tons/year, meanwhile, carbon dioxyde produced by human respiratory activities was $9,499.47$ ton/year. The necessary of urban forest area to absorb the amount of that emission is 12.67 hectare. Calculation of vegetation space approximately $10 \times 10$ $\mathrm{m}^{2}$, based on assumption that to absorb carbon dioxyde is in the central of city. Therefore to be recommended that the type of the urban forest is recreation forest type, in order to improve aestetic and convenience of the city in the future. The number of species to be planted is consists of 21 species, which $30 \%$ of the forest area will designed as an open space area for community interaction. Therefore, the number of trees to be planted is about 620.56 individu of tree.
\end{abstract}

Keywords: Urban forest; Carbon Dioxyde Emission; Vehicle; Vegetation

DOI:10.30598/jhppk.2019.3.2.114

ISSN ONLINE: 2621-8798

Page 114 


\section{PENDAHULUAN}

Terjadinya perubahan iklim yang menimbulkan bencana baru bagi manusia telah banyak dibuktikan secara ilmiah. Perubahan iklim terjadi karena peningkatan konsentrasi gas rumah kaca (GRK) yaitu CO2, CH4, N2O, HFC, PFC dan SF6 di atmosfer. Peningkatan emisi GRK diakibatkan oleh proses pembangunan dan industri berbahan bakar migas (BBM) yang semakin meningkat dan kegiatan penggunaan lahan serta alih guna lahan dan kehutanan (Ismayadi Samsoedin, Ari Wibowo, 2012). Pemerintah telah menargetkan penurunan emisi GRK sebesar $26 \%$ pada tahun 2020. Kontribusi sektor kehutanan dalam penurunan emisi GRK ini dilakukan dapat dengan mencegah terjadinya penambahan emisi melalui kegiatan pencegahan deforestasi dan degradasi serta kegiatan penanaman yang menyerap GRK dari atmosfer menjadi kayu.

Upaya mitigasi perubahan iklim, yaitu penurunan emisi gas rumah kaca dapat dilakukan, antara lain dengan memanfaatkan keberadaan pohon-pohonan di perkotaan yang memiliki peran penting sebagai penyerap karbon. Hal ini menambah manfaat pohon di perkotaan, selain sebagai penyejuk tata ruang, penghasil oksigen, habitat satwa, serta daerah resapan air.

Menurut Hairiah (2007), Ekosistem hutan merupakan suatu ekosistem yang sangat erat kaitannya dengan siklus karbon. Hutan mampu melakukan mekanisme sekuestrasi, yaitu mereduksi emisi karbon yang berlebihan di atmosfer dan mampu menyimpannya dalam berbagai kompartemen seperti tumbuhan, serasah, dan bahan organik tanah. Karbon dapat dijumpai di atmosfer dalam bentuk karbon dioksida. Adanya tumbuhan sebagai penyimpan karbon menyebabkan konsentrasi karbondioksida di atmosfer menurun.

Pembangunan kawasan hijau di daerah perkotaan merupakan langkah konkret yang penting untuk dilakukan, mengingat sebagian besar pembangunan yang dilakukan terkonsentrasi di wilayah perkotaan. Hutan kota merupakan salah satu bentuk dari RTH dan sudah ditetapkan oleh Pemerinta Pusat sebagai kewajiban bagi pemerintah Daerah untuk dibangun di tiap wilayah kota Provinsi dan Kabupaten di Indonesia. Hutan kota memiliki peranan penting dalam kehidupan perkotaan. Hal ini dikutip dari pendapat Dachlan (2013) dalam Yuniar Pratriwi (2016) hutan kota memiliki peranan yaitu: sebagai identitas kota, pelestarian plasma nutfah, penahan dan penyaring partikel padat dari udara, penyerap dan penjerap partikel timbal, debu semen dan bau, peredam kebisingan ,mengurangi bahaya ujan asam, penyerap karbon-monoksida, penyerap $\mathrm{CO} 2$ dan penghasil $\mathrm{O} 2$, penahan angin, mengatasi penggenangan dan intrusi air laut, produksi terbatas, ameliorasi iklim, pengelolaan sampah, pelestarian air tanah, penapis cahaya silau, meningkatkan 
keindahan, sebagai habitat burung, lahan untuk permukiman, perkantoran, sekolah, mengurangi stres, meningkatkan industri jalan, kawasan pertanian, dan industri serta pariwisata dan sebagai hobi dan pengisi waktu pembukaan ruas jalan baru yang luang. Permukiman, perkantoran, perdagangan mengakibatkan ketersediaan lahan untuk dan industri dianggap sebagai enklave yang kawasan hijau perkotaan atau kawasan resapan harus dihijaukan kembali agar fungsi hutan kota dapat terwujud secara nyata .

menjadi berkurang.

Pengelolaan ruang atau lanskap di

Dampak dari pembangunan salah satunya adalah pencemaran lingkungan. Pembangunan berbagai sarana dan prasarana menyebabkan meningkatnya kebutuhan akan lahan sehingga berkurangnya ruang terbuka hijau. Hal ini menyebabkan berkurangnya vegetasi sehingga mempengaruhi kualitas udara. Sehingga hutan kota yang adalah jenis Ruang Terbuka Hijau yang penting untuk mendukung kondisi lahan dengan komposisi jenis pohon yang memiliki keanekaragaman hayati yang tinggi, namun juga mampu mereduksi dampak pencemaran udara sehingga memberikan manfaat ekologis secara optimal.

Kota Piru merupakan ibu kota Kabupaten Seram Bagian Barat di Provinsi Maluku. Sebagai kota kabupaten, Piru memiliki konsekuensi dari keberadaan kota sebagai pusat berbagai aktivitas manusia di tingkat kabupaten. Tingginya aktivitas manusia menyebabkan pertumbuhan ekonomi yang pesat dan berpengaruh pada tingginya penggunaan sumber daya alam, selain juga meningkatnya aktivitas transportasi dan penggunaan lahan di wilayah Piru dan sekitarnya. Hal ini dapat dilihat dari alih fungsi

Piru mengalami tantangan dan hambatan yang cukup berat, salah satunya ialah bagaimana ruang perkotaan mampu tersedia secara proporsional tetapi disisi lain keberadaannya juga dapat mengimbangi tekanan lajunya pertumbuhan penduduk dan permintaan yang tinggi akan kebutuhan lahan. Perencanaan dalam penataan ruang di wilayah Piru sangat penting dikaji secara komprehensif, hal ini untuk menjawab dilema klasik pembangunan kota dimana lahan yang terbatas dikelola untuk mencukupi daya dukung pembangunan yang semakin tinggi. Menyediakan ruang terbuka hijau (RTH) merupakan salah satu langkah konkret yang harus dimulai sejak dini untuk mengurangi dampak negatif dari pembangunan di masa mendatang. Kota Piru yang saat ini sedang dalam tahap membangun memiliki permasalahan penataan ruang perkotaan. Belum adanya penetapan wilayah untuk Ruang Terbuka Hijau (RTH) menyebabkan penggunaan dan pemanfaatan ruang dalam menyiapkan kawasan hijau di wilayah kota menjadi terabaikan.

Tujuan dari penelitian ini adalah menentukan luas areal untuk pembangunan 
hutan kota dan jumlah tanaman yang proporsional untuk menyerap emisi karbondioksida di wilayah Piru dan sekitarnya. Hasil penelitian ini diharapkan dapat

\section{METODE PENELITIAN}

\section{Lokasi dan Waktu}

Penelitian ini dilaksanakan di Piru, Ibu kota Kabupaten Seram Bagian Barat, Provinsi Maluku, dan berlangsung selama 3 bulan, mulai dari bulan Februari sampai bulan April 2019.

\section{Metode Pengumpulan Data}

Pengumpulan data terbagi atas data primer dan data sekunder dimana data primer meliputi data lalulintas kendaraan dan populasi penduduk di Piru dan sekitarnya.

\section{1). Pengumpulan Data Primer}

Tahap awal dari estimasi emisi karbon buangan kendaraan bermotor adalah menghitung jumlah kendaraan bermotor yang beroperasi di lokasi pengamatan dengan menggunakan metode traffic counting. Kendaraan bermotor yang dihitung dibagi atas 3 golongan utama yaitu: (1) sepeda motor; (2) mini bus dan pickup; (3) bus dan truck. Kegiatan penghitungan kendaraan bermotor dilakukan di tiga lokasi pengamatan yaitu Jl. Hatutelu, Jl. Waemeten, dan Jl. J. Puttileihalat. Waktu penghitungan kendaraan bermotor adalah selama 5 hari dengan intensitas 6 jam per hari, yaitu jam pengamatan pagi pukul 06.30 - 08.30, jam memberikan informasi dan data hasil analisis tentang rencana pembangunan hutan kota Piru sebagai pertimbangan dalam evaluasi RTRW Kota Piru. pengamatan siang pukul $12.00-14.00$ dan jam pengamatan sore pukul 16.00 - 18.00, dengan asumsi waktu pengamatan adalah waktu dimana arus lalulintas mencapai puncak di jalan raya.

2). Pengumpulan Data Sekunder

Data sekunder yang dikumpulkan meliputi, data jumlah populasi kendaraan yang tercatat dimiliki oleh penduduk yang berdomisili di Kabupaten Seram Bagian Barat, data citra kondisi jalan di wilayah kota Piru.

\section{Metode Analisis Data}

a) Analisis Kuantitatif

Analisis kuantitatif yang digunakan dalam penulisan ini dipakai untuk menghitung emisi yang dihasilkan oleh lalulintas kendaraan digunakan rumus:

$$
Q=\text { Ni } \times \text { Fei } \times L \times K I
$$

Keterangan :

Q = Jumlah emisi (g/jam)

$\mathrm{Ni}=$ Jumlah kendaraan bermotor

(kendaraan/jam) 
Fei $=$ Faktor emisi kendaraan bermotor (g/liter)

$\mathrm{Kl}=$ Konsumsi bahan bakar kendaraan bermotor (liter/100 km)

$\mathrm{L}=$ Panjang Jalan $(\mathrm{Km})$

Selanjutnya menghitung emisi
karbondioksida dari aktivitras pernapasan
manusia, dengan memperhitungkan faktor emisi
dari pernapasan manusia.

\section{HASIL DAN PEMBAHASAN}

\section{Estimasi Emisi Kendaraan Bermotor}

1) Jumlah Kendaraan

Estimasi emisi karbon dilakukan dengan analisa kuantitatif yang diperkuat dengan asumsi yang rasional dan dibuat berdasarkan kondisi riil dilapangan. Perhitungan terhadap jumlah emisi karbondioksida adalah sebagai acuan untuk mengestimasi luasnya kebutuhan akan hutan kota sesuai tujuan analisis.

Hasil perhitungan mengenai jumlah kendaraan yang dihitung menggunakan metode traffic count dapat dilihat pada tabel 1 sebagai berikut :

Tabel 1. Jumlah Kendaraan Bermotor Melintas di Lokasi Pengamatan

\begin{tabular}{|c|c|c|c|c|c|c|c|}
\hline \multirow{2}{*}{ No } & \multirow{2}{*}{$\begin{array}{c}\text { Lokasi } \\
\text { Pengamatan }\end{array}$} & \multicolumn{3}{|c|}{$\begin{array}{c}\text { Golongan Kendaraan } \\
\text { (6jam/hari) }\end{array}$} & \multicolumn{3}{|c|}{$\begin{array}{c}\text { Golongan Kendaraan } \\
\text { (1 jam/hari) }\end{array}$} \\
\hline & & $\begin{array}{l}\text { Sepeda } \\
\text { Motor }\end{array}$ & $\begin{array}{l}\text { Mini bus } \\
\text { Pickup }\end{array}$ & $\begin{array}{l}\text { Bus } \\
\text { Truck }\end{array}$ & $\begin{array}{l}\text { Sepeda } \\
\text { Motor }\end{array}$ & $\begin{array}{l}\text { Mini bus } \\
\text { Pickup }\end{array}$ & $\begin{array}{l}\text { Bus } \\
\text { Truck }\end{array}$ \\
\hline 1. & Zona A & 1.743 & 316 & 87 & 290 & 53 & 14 \\
\hline 2. & Zona B & 1.567 & 269 & 73 & 281 & 45 & 12 \\
\hline \multirow[t]{2}{*}{3.} & Zona C & 707 & 165 & 98 & 118 & 27 & 16 \\
\hline & & 4.017 & 750 & 258 & 669 & 125 & 43 \\
\hline
\end{tabular}

Sumber: Data Olahan, 2019

Dari tabel 1 diatas, dapat diketahui jumlah sepeda motor yang melintas di lokasi penghitungan sebanyak 4.017 unit, dimana intensitas paling tinggi adalah yang melintas di Jl. Hatutelu dengan jumlah 1.743 unit. Sama halnya dengan jumlah hitung kendaraan jenis minibus dan pickup dimana dari 3 lokasi penghitungan, jumlah terbanyak ialah yang melintas di Jl. Hatutelu, hal ini disebabkan karena di lokasi Jl. Hatutelu merupakan jalan utama dari dan menuju ke permukiman penduduk, Sekolah Dasar, Sekolah Menengah Pertama, Perkantoran,
Terminal dan Pasar Piru. Sedangkan untuk golongan kendaraan jenis bus dan truck memiliki intensitas lalulintas paling banyak di Jl. J. Puttileihalat, hal ini karena akses bus antar Kabupaten SBB dan Kabupaten Maluku Tengah, antar kabupaten SBB dengan Kota Ambon yang setiap jam melintas melewati jalan tersebut serta aktivitas truk terkait operasional tambang material pasir dan batu di sekitar DAS Wae Ety. 


\section{2) Proyeksi Kendaraan Bermotor}

Proyeksi kendaraan bermotor dilakukan untuk menghitung dugaan peningkatan jumlah kendaraan jangka waktu 10 tahun kedepan, dengan asumsi pada akhir periode tanaman hutan kota telah mencapai kategori pohon, hal ini dimungkinkan dengan munculnya jenis-jenis pohon cepat tumbuh atau jenis Fast Growth Species yang rata-rata dapat dipanen pada saat umur 10 tahun. Proyeksi jumlah kendaraan dihitung dengan menggunakan metode goemetrik sebagai berikut:

$$
\operatorname{Pn}=\mathbf{P o}(1+r)^{\mathbf{n}}
$$

Dimana:

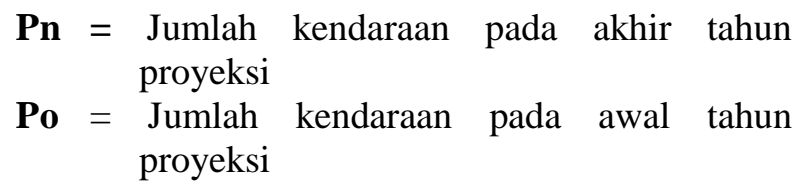

$\mathbf{r} \quad=$ Rata-rata pertambahan penduduk tiap tahun $\mathbf{n}=$ Jangka waktu proyeksi

Dari rumus diatas dapat diketahui yang menjadi acuan perhitungan proyeksi adalah jumlah kendaraan awal tahun proyeksi dan rasio pertumbuhan penduduk setempat. Penghitungan rasio penduduk dengan menggunakan rata-rata pertumbuhan penduduk jangka waktu 3 tahun terakhir yang paling tinggi yaitu sebesar 1,06\%, Sedangkan untuk jumlah kendaraan digunakan data kendaraan bermotor berdasarkan wajib pajak di

\begin{tabular}{|c|c|c|c|c|}
\hline \multirow[b]{2}{*}{ Tahun } & \multicolumn{4}{|c|}{ Jumlah Kendaraan Bermotor Berdasarkan Jenis } \\
\hline & $\begin{array}{r}\text { Sepeda } \\
\text { Motor }\end{array}$ & $\begin{array}{l}\text { Minibus } \\
\text { Pickup }\end{array}$ & & \\
\hline 2018 & 7.732 & 785 & 227 & (1) \\
\hline 2028 & 8.732 & 873 & 252 & $(2)$ \\
\hline
\end{tabular}
Kabupaten Seram Barat tahun 2018, hasil perhitungan proyeksi kendaraan bermotor dapat dilihat pada Tabel 2 di bawah ini:

Tabel 2. Jumlah Kendaraan Bermotor Tahun 2018

Dari data tabel di atas, dapat diketahui jumlah kendaraan sepeda motor tahun 2028 mengalami kenaikan sebesar 11,45\%, sedangkan untuk jenis kendaraan minibus-pickup, dan truckbus masing-masing mengalami peningkatan sebesar $10,08 \%$ dan $9,92 \%$.

\section{3) Faktor Emisi dan Konsumsi Bahan Bakar Kendaraan Bermotor}

Sesuai persamaan emisi kendaraan bermotor yang dipakai, maka hal yang perlu diketahui adalah konstanta dalam perhitungan, yaitu faktor emisi (Fei) dan konsumsi bahan bakar kendaraan bermotor (Kl). Faktor emisi dan konsumsi bahan bakar kendaraan yang dipakai sesuai dengan Pedoman Teknis Penyusunan Inventarisasi Emisi Pencemaran Udara di Perkotaan (KLH, 2013), yaitu sebagai berikut: 
Tabel 3. Faktor Emisi dan Konsumsi Bahan Bakar Kendaraan Bermotor

\begin{tabular}{c|c|c|c|c}
\hline \multirow{2}{*}{ No } & \multirow{2}{*}{ Jenis Kendaraan } & \multicolumn{2}{|c|}{ Faktor Emisi $\mathrm{CO}_{2}$} & \multirow{2}{*}{$\begin{array}{c}\text { Konsumsi Energi } \\
\text { Spesifik }(\mathrm{Km} / \mathrm{L})\end{array}$} \\
\cline { 3 - 4 } & & $\mathrm{g} / \mathrm{Kg} \mathrm{BBM}$ & $\mathrm{g} / \mathrm{L} \mathrm{BBM}$ & 28 \\
\hline 1 & Sepeda Motor & 3.180 & $2.302,32$ & 8,5 \\
\hline 2 & Minibus & 3.178 & $2.300,87$ & 8,5 \\
\hline 3 & Pickup & 3.178 & $2.300,87$ & 4 \\
\hline 4 & Bus & 3.172 & $2.639,10$ & 4 \\
\hline 5 & Truck & 3.172 & $2.639,10$ & \\
\hline
\end{tabular}

Sumber: KLH, 2013.

Faktor emisi dalam petunjuk teknis hanya menyertakan satuan gram/Kg BBM, sehingga untuk mengestimasi konsumsi energi dalam liter, faktor emisi harus dikonversi ke satuan gram/liter BBM.
Konversi tersebut dihitung dengan mengalikan faktor emisi dengan massa jenis bahan bakar yang digunakan yaitu bensin $0,724 \mathrm{Kg} / \mathrm{L}$ dan solar 0,832 $\mathrm{Kg} / \mathrm{L}$.

\section{4) Perhitungan Beban Emisi}

Tabel 4. Jumlah Emisi $\mathrm{CO}_{2}$

\begin{tabular}{|c|c|c|c|c|}
\hline Zona & $\begin{array}{l}\text { Panjang Jalan } \\
(\mathrm{Km})\end{array}$ & Jenis Kendaraan & $\begin{array}{c}\text { Jumlah } \\
\text { Kendaraan } \\
\text { /jam } \\
\end{array}$ & $\begin{array}{c}\text { Jumlah } \\
\text { Emisi } \mathrm{CO}_{2}(\mathrm{~g} / \mathrm{jam})\end{array}$ \\
\hline \multirow{3}{*}{ A } & \multirow{3}{*}{4,15} & Sepeda Motor & 290 & $84.126 .772,80$ \\
\hline & & Minibus-Pickup & 53 & $4.629 .235,40$ \\
\hline & & Bus-Truck & 14 & $687.221,64$ \\
\hline \multirow{3}{*}{ B } & \multirow{3}{*}{3,1} & Sepeda Motor & 281 & $52.158 .599,14$ \\
\hline & & Minibus-Pickup & 45 & $2.720 .172,88$ \\
\hline & & Bus-Truck & 12 & $392.698,08$ \\
\hline \multirow{4}{*}{$\mathrm{C}$} & \multirow{3}{*}{7,75} & Sepeda Motor & 118 & $58.953 .205,92$ \\
\hline & & Minibus-Pickup & 27 & $4.112 .594,21$ \\
\hline & & Bus-Truck & 16 & $1.330 .810,16$ \\
\hline & & & Jumlah & $209.111 .310,22$ \\
\hline
\end{tabular}

Sumber: Data olahan, 2019.

Dari hasil perhitungan seperti yang disajikan dalam Tabel 4 diatas, dapat diketahui jumlah emisi karbondioksida yang dihasilkan oleh kendaraan bermotor adalah sebesar 209.111.310,22 g/jam atau setara dengan 209, 11 ton/jam. Dari hasil tersebut juga dapat diestimasi emisi $\mathrm{CO}_{2}$ yang dihasilkan pertahun dengan asumsi: (1) lamanya kendaraan beroperasi setiap hari adalah 1 jam; dan (2) lamanya kendaraan beroperasi selama 1 bulan adalah 20 hari, yaitu sebesar 50.186,4 ton/tahun. Pembagian emisi $\mathrm{CO}_{2}$ berdasarkan zona masingmasing wilayah adalah Zona A sebesar 89,44 ton/jam, Zona B sebesar 55,27 ton/jam, dan Zona C adalah sebesar 64.39 ton/jam.

\section{Estimasi Emisi Karbondioksida Pernapasan Manusia}

$$
\text { Perhitungan } \mathrm{CO}_{2} \text { yang dihasilkan }
$$
pernapasan manusia didasari dengan asumsi bahwa setiap manusia mengeluarkan $\mathrm{CO}_{2}$ adalah sama. 
Penghitungan emisi yang dihasilkan dari pernapasan manusia menggunakan persamaan menurut Dahlan (1992) yaitu:

- Emisi (kg/hari) : Jumlah

- Emisi (gr/jam) : Jumlah penduduk x 0,9504 kg/hari

- Emisi (ton/tahun) : Jumlah penduduk x 39,60 gr/jam penduduk x 0,347 ton/tahun

Tabel 5. Jumlah Emisi Pernapasan manusia

\begin{tabular}{|c|c|c|c|c|}
\hline No. & $\begin{array}{c}\text { Jenis Emisi } \\
\text { Buangan } \\
\end{array}$ & $\begin{array}{c}\text { Jumlah } \\
\text { Populasi }{ }^{(1)}\end{array}$ & Faktor Emisi ${ }^{(2)}$ & Jumlah Emisi $^{(3)}$ \\
\hline \multirow[t]{3}{*}{1.} & \multirow{3}{*}{$\begin{array}{l}\text { Pernapasan } \\
\text { Manusia }\end{array}$} & \multirow[t]{3}{*}{27.376} & $39,60 \mathrm{gr} / \mathrm{jam}$ & $1.084 .089,6 \mathrm{gr} / \mathrm{jam}$ \\
\hline & & & $0,9504 \mathrm{~kg} / \mathrm{hari}$ & $26.018,15 \mathrm{~kg} / \mathrm{hari}$ \\
\hline & & & 0,347 ton/tahun & $9.499,47$ ton/tahun \\
\hline
\end{tabular}

(1) Kecamatan Seram Barat dalam Angka, 2018

(2) E.N. Dahlan, 2007

(3) Data olahan, 2019

Kemampuan Serapan $\mathrm{CO}_{2}$ Vegetasi Hutan Kota

Berikut adalah beberapa jenis pohon yang

direkomendasikan untuk pembangunan hutan kota

Piru, dimana jenis vegetasi yang dipilih merupakan jenis yang sudah dapat dihitung tingkat penyerapan karbonnya, berdasarkan hasil penelitian terdahulu.

Tabel 6. Jenis Pohon Berdasarkan Tingkat Serapan $\mathrm{CO}_{2}$

\begin{tabular}{|c|c|c|c|c|}
\hline No. & Nama Lokal & Nama Ilmiah & \multicolumn{2}{|c|}{$\begin{array}{c}\text { Daya Serap } \mathrm{CO}_{2} \\
\text { (g/jam.pohon) }\end{array}$} \\
\hline 1. & Trembesi & Samanea saman & $3.252,14$ & (1) \\
\hline 2. & Mahoni & Swietenia macrophylla & $3.112,43$ & (2) \\
\hline 3. & Beringin & Ficus benjamina & $1.146,51$ & (2) \\
\hline 4. & Mangga & Mangifera indica & 51,96 & (3) \\
\hline 5. & Pulai & Alstonia scholaris & $1.319,35$ & (2) \\
\hline 6. & Flamboyan & Delonix regia & 59,96 & (2) \\
\hline 7. & Cemara laut & Casuarina equisetifolia & 45 & (4) \\
\hline 8. & Tanjung & Mimusops elengi & 67,58 & (3) \\
\hline 9. & Pucuk Merah & Oleina syzygium & 155,58 & $(5)$ \\
\hline 10. & Jambu Biji & Syzygium malaccense & 44,59 & (2) \\
\hline 11. & Sukun & Artocarpus altilis & 22 & (4) \\
\hline 12. & Bambu Cina & Bambusa multiplex & 0,39 & (4) \\
\hline 13. & Lamtoro & Leucaena leucocephala & 165 & (4) \\
\hline 14. & Daun Kupu-kupu & Bauhinia purpurea & $1.331,38$ & (2) \\
\hline 15. & Palem Phoenix & Phoenix roebelenii & 0,39 & (4) \\
\hline 16. & Kersen & Muntingia calabura & 0,6 & (4) \\
\hline 17. & Palem Bambu & Chamaedorea seifrizii & 0,39 & (4) \\
\hline 18. & Jati & Tectona grandis & 12,41 & (3) \\
\hline 19. & Jabon & Anthocepallus cadamba & 9,95 & (4) \\
\hline 20. & Angsana & Pterocarpus indicus & 310,52 & (2) \\
\hline 21. & Ketapang & Terminalia sp. & 24,16 & (4) \\
\hline \multicolumn{5}{|c|}{ Sumber: } \\
\hline
\end{tabular}

DOI:10.30598/jhppk.2019.3.2.114

ISSN ONLINE: 2621-8798 


\section{Konsep Design Hutan Kota Piru}

Setelah mengetahui jumlah emisi karbondioksida yang dihasilkan maka selanjutnya dilakukan penghitungan kebutuhan vegetasi untuk menyerap emisi yang dihasilkan. Dalam menentukan jumlah vegetasi hutan kota, langkah pertama yang diambil yaitu pemilihan tapak, penentuan luasan dan pemilihan tipe atau bentuk hutan kota akan dibangun. Sebagai contoh pemilihan tapak yang berada di tengah kota, dan bentuk hutan kota yang dipilih yaitu tipe rekreasi dan perlindungan, Tipe rekreasi lebih mengedepankan bentuk yang terbuka dengan banyaknya ruang interaksi untuk fasilitas rekreasi seperti arena bersepeda, jogging, fasilitas olahraga seperti badminton dan basket serta tempat bermain dan belajar anak-anak, sehingga bentuk tajuk dari ruang hijaunya akan sedikit meyebar dan terbuka dibandingkan dengan tipe hutan kotayang lain. Bandingkan dengan hutan kota tipe perlindungan, dimana manfaat yang ingin didapat yaitu fungsi perlindungan, perlindungan keanekaragaman hayati, baik tumbuhan maupun satwa, konservasi tanah dan air, sebagai daerah resapan dan lain-lain. Tipe ini mememiliki bentuk tajuk yang relatif rapat antara 90-100\%, dapat diajukan sebagai kawasan yang tertutup untuk interaksi masyarakat didalamnya. Kedua ini dapat direkomendasikan sebagai bentuk atau tipe hutan kota yang akan dibangun di kota Piru, kedua tipe tersebut merupakan pilihan yang proporsional di areal yang belum terbangun, tergantung manfaat yang paling ingin didapat dari keberadaan hutan kota itu sendiri.

Bentuk hutan kota juga dapat disesuaikan dengan kondisi landskap atau bentang lahan kota, misalnya untuk kawasan dengan kelerengan yang relatif miring sampai curam, tentu akan lebih proporsional untuk tujuan perlindungan, dibandingkan dengan tujuan interaksi dengan masyarakat. Sedangkan jika jarak lokasi pembangunan dengan permukiman masyarakat cukup dekat, maka hutan kota yang dibangun dapat merekomendasikan tipe rekreasi, sehingga memudahkan akses masyarakat untuk dapat berinteraksi didalamnya. Kondisi bentang lahan serta manfaat yang ingin diperoleh, membantu mengidentifikasi tujuan pembangunan hutan secara komprehensif, sehingga selain manfaat ekologis yang diperoleh, manfaat interaksi masyarakat dengan hutan kota dapat menambah indeks kenyamanan kota kedepan, disamping fungsi estetika dan penyerapan karbon.

\section{Kebutuhan Vegetasi Hutan Kota Piru}

Dari estimasi emisi yang dihasilkan oleh aktivitas lalu lintas kendaraan bermotor dan aktivitas pernapasan manusia, diperoleh nilai emisi rata-rata pertahun masing-masing sebesar 50.186,4 ton/tahun dan 9.499,47 
ton/tahun atau total sebesar 59.685,87 ton/tahun. Dengan komposisi keanekaragaman vegetasi seperti pada Tabel 6, dimana secara matematik jumlah emisi karbon yang dapat diserap adalah 96,18 ton/tahun, maka jumlah vegetasi yang harus dipenuhi dalam hutan kota untuk menyerap karbondioksida $\left(\mathrm{CO}_{2}\right)$ seperti tersebut, yaitu sebanyak 59.685,87 dibagi 96,18 sama dengan 620,56 individu, dengan asumsi jumlah individu setiap spesies adalah sama. Jika demikian, maka jumlah individu dari 21 spesies yang direkomendasikan masing-masing adalah sebanyak 29,55 individu.

Proporsional luasan hutan kota yang akan dibangun juga harus memperhatikan kemampuan penyerapan karbondioksida dari komposisi yang akan dibangun. Untuk tingkat penyerapan emisi $\mathrm{CO} 2$ tersebut diatas, maka luas yang sesuai sehingga dapat mencakup seluruh populasi vegetasi penyerap emisi yang direkomendasikan adalah sebesar 12,67 $\mathrm{Ha}$ untuk tipe rekreasi, dengan asumsi, antara lain:

- Jarak tanam vegetasi pohon $10 \times 10$ meter (jarak rata-rata, dimana sesuai RTH tipe Hutan Kota, rekomendasi jarak maksimum 12 x 12 meter dan minimum $6 \times 6$ meter sesuai tipe hutan kota yang dibangun).

- $30 \%$ disetiap hamparan hutan kota merupakan ruang terbuka, untuk keperluan ruang interaksi bagi masyarakat,
- Komposisi jenis spesies vegetasi yang ditanam sesuai Tabel 6

Dengan demikian sesuai komposisi vegetasi yaitu sebanyak 21 spesies, maka untuk luasan 12,67 Ha, diperlukan kurang lebih 48,98 pohon/Ha dari setiap spesies yang direkomendasikan, atau setiap spesies sekitar 3,33 pohon untuk setiap heaktarnya. Jenis vegetasi hutan kota juga dapat disesuaikan dengan jenis endemik lokal, pohon buah, serta pohon yang memiliki perakaran dalam, dan pohon yang tidak diprioritaskan pemanfaatan kayunya.

\section{Kebutuhan Hutan Kota Berdasarkan Proyeksi Kendaraan dan Populasi penduduk}

Dari hasil proyeksi jumlah kendaraan berdasarkan peningkatan jumlah penduduk di wilayah Kabupaten Seram Bagian Barat, maka dapat dihitung kebutuhan luas hutan kota untuk menyerap emisi karbondioksida buangan periode 10 tahun kedepan. Hasil proyeksi kendaraan bermotor untuk sepeda motor, minibus/pickup, dan bus/truck masingmasing adalah $11,45 \%, 10,08 \%$ dan $9,92 \%$, sedangkan proyeksi pertumbuhan jaringan jalan di Maluku rata-rata adalah sebesar 9\% per tahun (Setditjen Perhubungan Darat, 2013). Namun pertumbuhan jaringan jalan di Kota Piru juga didasarkan pada daya dukung dan kapasitas ruang serta RTRW Kabupaten 
Seram Bagian Barat. Piru merupakan Kota kabupaten yang tergolong baru, sehingga kebutuhan akan jaringan jalan menjadi prioritas pemerintah untuk meningkatkan kapasitas wilayah kedepan. Pertumbuhan jaringan jalan yang dimungkinkan untuk diproyeksikan semakin tinggi adalah jaringan jalan yang terhubung pada zona B dan C yang tergolong wilayah pengembangan kota, dibandingkan dengan zona A yang didominasi oleh permukiman penduduk. Dari kondisi tersebut maka dapat diproyeksikan emisi karbon yang dihasilkan di kota Piru pada tahun 2028 sebagai dasar estimasi luas kebutuhan hutan kota adalah sebagai berikut

Tabel 7. Proyeksi Jumlah Emisi $\mathrm{CO}_{2}$ di Kota Piru Tahun 2028

\begin{tabular}{|c|c|c|c|c|}
\hline Zona & $\begin{array}{c}\text { Panjang Jalan } \\
(\mathrm{Km})\end{array}$ & Jenis Kendaraan & $\begin{array}{l}\text { Jumlah } \\
\text { Kendaraan } \\
\text { /jam }\end{array}$ & $\begin{array}{c}\text { Jumlah } \\
\text { Emisi } \mathrm{CO}_{2}(\mathrm{~g} / \mathrm{jam})\end{array}$ \\
\hline \multirow{3}{*}{ A } & \multirow{3}{*}{9,82} & Sepeda Motor & 857 & $542.520 .342,47$ \\
\hline & & Minibus-Pickup & 138 & $26.503 .399,41$ \\
\hline & & Bus-Truck & 36 & $3.731 .898,53$ \\
\hline \multirow{3}{*}{ B } & \multirow{3}{*}{7,34} & Sepeda Motor & 831 & $393.206 .602,12$ \\
\hline & & Minibus-Pickup & 118 & $16.939 .050,96$ \\
\hline & & Bus-Truck & 31 & $2.402 .003,26$ \\
\hline \multirow{4}{*}{$\mathrm{C}$} & \multirow{3}{*}{18,35} & Sepeda Motor & 349 & $412.843 .273,58$ \\
\hline & & Minibus-Pickup & 71 & $25.480 .352,08$ \\
\hline & & Bus-Truck & 41 & $7.942 .107,54$ \\
\hline & & & Jumlah & $1.431 .569 .029,94$ \\
\hline
\end{tabular}

Sumber: Data olahan, 2019.

Dari tabel diatas dapat diketahui proyeksi jumlah emisi karbondioksida di Kota Piru Tahun 2028 adalah sebesar 1.431.569.029,94 $\mathrm{g} / \mathrm{jam}$ atau setara dengan 2.576.824,25 ton/tahun. Dengan metode proyeksi yang sama, jumlah penduduk dengan rata-rata pertumbuhan $0,31 \%$ per tahun, maka jumlah penduduk Kecamatan Seram Barat tahun 2028 diprediksi mencapai 28.237, yang menghasilkan emisi karbondioksida dari aktivitas pernapasan sebesar 9.798,24 ton/tahun.

Dengan komposisi jenis vegetasi yang sama seperti pada Tabel 6, maka jumlah vegetasi yang harus ditanam untuk menyerap emisi karbondioksida ditahun 2028 adalah sebanyak 26.893,56 individu. Jika asumsi yang dipakai sama untuk tipe rekreasi dengan jarak tanam $10 \times 10$ meter dimana $30 \%$ untuk ruang interaksi maka luas hutan kota adalah 384,19 hektar. Jumlah diatas akan lebih sedikit, jika tipe hutan kota yang dipilih adalah tipe perlindungan dengan ciri tapak memiliki tajuk yang relatif rapat, maka jarak tanam yang direkomendasikan adalah 6 × 6 meter dimana $10 \%$ dari luas areal hutan kota diperuntukan untuk ruang interaksi, sehingga luas hutan kota yang harus dibangun di Piru adalah sebesar 107,57 Hektar 


\section{KESIMPULAN DAN SARAN}

\section{Kesimpulan}

Hasil penghitungan menunjukan jumlah emisi karbondioksida yang dihasilkan oleh lalulintas kendaraan di Kota Piru adalah sebesar 50.186,4 ton/tahun, sedangkan emisi karbondioksida yang dihasilkan oleh pernapasan manusia adalah sebesar 9.499,47 ton/tahun. Untuk menyerap karbondioksida tersebut, maka luas hutan yang direkomendasikan adalah sebesar 12,67 Ha, dengan jumlah vegetasi sebanyak 620,56 individu yang terdiri dari 21 jenis dimana jarak tanam adalah $10 \times 10$ meter dengan 30\% ruang hijaunya diperuntukan sebagai ruang terbuka untuk interaksi masyakat di dalamnya seperti rekreasi dan olahraga. Sebagai asumsi tambahan pemilihan tapak untuk penyerapan emisi karbondioksida terletak ditengah kota, sehingga tipe yang direkomendasikan adalah tipe rekreasi, yang secara komprehensif dapat menambah nilai estetika, serta menambah kenyamanan kota Piru kedepan.

\section{DAFTAR PUSTAKA}

[BPS] Badan Pusat Statistik. 2018. Seram Bagian Barat Dalam Angka Tahun 2018. Kabupaten Seram Bagian Barat. Provinsi Maluku.

[BPS] Badan Pusat Statistik. 2018. Kecamatan Seram Barat Dalam Angka Tahun 2018. Kabupaten Seram Bagian Barat. Provinsi Maluku.

Dachlan. E.N 2007. Analisis Kebutuhan Luasan Kota Sebagai Sink Gas CO2 Antropogenik dari Bahan Bakar Minyak
Proyeksi emisi karbondioksida di Kota

Piru Tahun 2028 adalah sebesar 2.586.622,49 ton/tahun, ekuivalen dengan hutan kota seluas 384,19 ha untuk tipe rekreasi dengan jarak tanam $10 \times 10$ meter dimana 30\% ruang untuk interaksi masyarakat, sedangkan untuk tipe perlindungan luas hutan kota yang harus dibangun adalah 107,57 ha dengan jarak tanam $6 \times 6$ meter dan intensitas ruang hijau sebesar $90 \%$.

\section{Saran}

1. Bagi Pemerintah Daerah agar mulai membangun Hutan Kota sebagai bagian dari tanggung jawab bersama melestarikan bumi dan keanekaragaman hayati didalamnya.

2. Dalam pembangunan hutan kota Piru, Pemerintah perlu mengkaji luas, jenis dan jumlah vegetasi yang akan direkomendasikan, sehingga manfaat yang dicapai dapat mengimbangi tingkat pencemaran akibat aktivitas manusia dan dampak dari pembangunan.

dan Gas di Kota Bogor dengan Pendekatan Sistem Dinamik. Disertasi Program Studi Ilmu Pengetahuan Kehutanan, Sekolah Pasca Sarjana. IPB. Bogor.

Gratimah. G. RD. 2009. Analisis Kebutuhan Hutan Kota Sebagai Penyerap Gas Co2 Antropogenik di Pusat Kota Medan. Tesis. Fakultas Matematika dan IPA. USU. Medan. 
Hairiah, K. 2007. Perubahan Iklim Global: Neraca Karbon di Ekosistem Daratan. Jurusan Tanah Fakultas Pertanian Universitas Brawijaya. Malang.

Ismayadi Samsoedin dan Ari Wibowo. 2012. Analisis Potensi Dan Kontribusi Pohon Di Perkotaan Dalam Menyerap Gas Rumah Kaca. Studi Kasus: Taman Kota Monumen Nasional, Jakarta. Jurnal Penelitian Sosial dan Ekonomi Kehutanan Vol. 9. Pusat Penelitian Perubahan Iklim dan Kebijakan. Bogor.

Karyadi H. 2005. Pengukuran Daya Serap Karbondioksida Lima Jenis Tanaman Hutan Kota. Departemen Konservasi Sumderdaya Hutan dan Ekowisata. IPB.Bogor.

[KLH] Kementerian Lingkungan Hidup. 2013. Pedoman Teknis Penyusunan Inventarisasi Emisi Pencemaran Udara Di Perkotaan. Deputi Bidang Pengendalian Pencemaran Lingkungan. Jakarta.
Pemerintah Republik Indonesia, 2002. Peraturan Pemerintah Nomor 63 Tahun 2002 tentang Hutan Kota.

Pemerintah Republik Indonesia, 2007. Undangundang Nomor 26 Tahun 2007 tentang Penataan Ruang.

Pemerintah Republik Indonesia, 2008. Peraturan Menteri Pekerjaan Umum Nomor 05/PRT/M/2008 tentang Pedoman Penyediaan dan Pemanfaatan RTH di Kawasan Perkotaan.

Purwaningsih. S. 2007. Kemampuan Serapan Karbondioksida Pada Tanaman Hutan Kota di Kebun Raya Bogor. Departemen Konservasi Sumberdaya Hutan dan Ekowisata. IPB. Bogor.

Yuniar Pratiwi. 2016. Analisis Kebutuhan Hutan Kota Berdasarkan Emisi Karbondioksida di Kota Prabumulih Provinsi Sumatera Selatan. Tesis. Institut Pertanian Bogor. Bogor. 